\title{
Analysis on critical gap for pedestrian crossing at Gandul intersection leg
}

\author{
Yohanes Elia Purwanto ${ }^{1}$ and Martha Leni Siregar ${ }^{1, *}$ \\ ${ }^{1}$ Department of Civil Engineering, Universitas Indonesia, Indonesia
}

\begin{abstract}
Pedestrian is one part of transportation system that its existence and importance should not be ignored in the transportation system planning process. Crossing facility at intersection which not equipped with traffic signal are high risk area for pedestrians. This paper discuss about gap that can be received by pedestrians when they will cross the road by analyzing the movement of vehicles in the traffic flow. Data are taken by video recording and direct observation on the intersection. The authors study and use several methods that have been used in previous literatures: Raff's method, Harder's method, and Wu's method. The authors analyze and compare the results of those method to find which one is the most appropriate to the actual condition. The results show the value of critical gap from each methods and the factors which affect it.
\end{abstract}

\section{Introduction}

Pedestrian is one part of the transportation system that its existence and interests should not be neglected in the transportation system planning process. WHO mentions that around 250 thousand pedestrians are involved in accidents every year [1] and most pedestrians are injured at crossings on a street or a road. Pedestrians are not protected hence are the group of road users that fall into the category of vulnerable road users. Special facilities for pedestrians are required either in the form of lane/ pavement for walking and facilities for crossings such as zebra cross, pelican crossing, and crossing bridge.

According to the data from Jakarta government, in 2017 there are only seven percents of the pedestrian lane for 7200 kilometers road [2]. Apart from serving the function, the design of pedestrian facilities has to take into account the need for comfort and safety. Crossing facilities at intersections which are not equipped with traffic signals are high-risk areas for pedestrians as when they are crossing the street and pedestrians are required to decide when he can safely cross.

This paper will discuss how big the gap between the position of crossing point and the position of the moving vehicle required or can be accepted by pedestrians in the decision making when crossing the road. The purpose of this paper is to determine the critical gap needed by pedestrians to conduct a safe crossing using different methods.

\footnotetext{
* Corresponding author: leni@eng.ui.ac.id
} 


\section{Literature review}

\subsection{Pedestrian}

From the transportation point of view, pedestrians are a person or group of people who move from one place to another on foot along the pedestrian path, and the movement is either in the form of walking down the road or crossing the road. Pedestrian facilities include several aspects such as pedestrian facilities, pedestrian paths, pedestrian flow, sidewalks, pedestrian crossings, and waiting areas. Some of the pedestrian parameters to consider in the design and planning of pedestrian facilities include the pedestrian walking speed, pedestrian flow, density, and pedestrian space.

Pedestrian perceptions need to be taken into consideration in the planning of pedestrian facilities such as the current speed, current, density, and pedestrian space used for theoretical planning. Decision making to cross the road is influenced by two factors namely internal factors (age, gender, physical condition, psychological condition) and external factors such as traffic conditions [3].

\subsection{Gap}

The gap is a time interval calculated from the moment the pedestrian will cross right until the nearest vehicle moves to the point of crossing. Decisions taken by pedestrians related to crossings depend on existing gap conditions (available gaps, acceptable gaps, and rejected gaps). The critical gap is the smallest gap that can be accepted by pedestrians to cross the existing traffic conditions [4].

\subsubsection{Raff's Method}

One method for analyzing critical gaps is to use graphical methods applied by Raff and Hart [5] as outlined in Traffic and Highway Engineering. Data plotted into graphs is denied gap data and gaps accepted. In the graphical method, there are two cumulative curves, one of which is connecting the length of gap/ lag time with the number of gaps received less than $t$ seconds and the other connecting $t$ with the number of rejected gaps larger than $t$. Crossing these two curves gives a value of $t$ for a critical gap.

\subsubsection{Harder's Method}

This method is based only on the value of accepted gaps. Harder uses the assumption that all drivers (in this study the driver's position is replaced with pedestrians) reject all gaps of less than 1 second and receive all gaps of more than 21 seconds. Harder uses a curve representing a cumulative distribution function [6-8].

\subsubsection{Wu's Method}

The theoretical background of this model is the probability equilibrium between rejected and acceptable gaps. Equilibrium is generated macroscopically based on the cumulative distribution of the received and rejected gaps. The $\mathrm{Wu}$ method has a solid theoretical background and results and is independent of the presumption of other models. This method is an alternative to MLM methods without the need for complex calculations and can be operated with a simple spreadsheet. This method does not require the consistency of 
a homogeneity fund from the rider's behavior (in this case pedestrian crossing) and can be used on a small sample of data [6-9].

\section{Research methods}

Observations were made at the unsignalized intersection of Jalan Raya Gandul - Jalan Bukit Cinere Raya, Cinere, Depok. The survey was carried out during peak hours at 07.0008.00 and 16.00-17.00, and non-peak hour at 11.00-12.00. The survey conducted for seven days with the duration per day is 1 hour, so the total observation time is 7 hours. Field surveys were conducted to obtain the necessary data to be analyzed and to support the study of critical gaps in pedestrian crossing cases at intersections. The data are the volume of the pedestrian crossing, pedestrian travel time, gap between the pedestrian with the vehicle. The tools used to support the survey are as follows: stopwatch, video camera, measuring instrument, and counter.

The survey method used is a direct observation in the field and recording traffic conditions on one of the intersection legs using a video camera. Counting the number of vehicles and pedestrians crossing is done using a counter by playing back the recorded video. The gap value is obtained by using a stopwatch, and the data such as the dimension of the road and the distance of the path crossing are obtained by direct measurements in the field. The gap value is counted when the pedestrian(s) start to walk to cross the street and stopped when the closest vehicle passes that crossing spot.

\section{Results and discussion}

Table 1. Observation data.

\begin{tabular}{|c|c|c|c|c|c|c|}
\hline No & $\begin{array}{c}\text { Pedestrian } \\
\text { quantity }\end{array}$ & $\begin{array}{c}\text { Age } \\
\text { category }\end{array}$ & Gender & $\begin{array}{c}\text { Gap } \\
\text { (second) }\end{array}$ & $\begin{array}{c}\text { Type of } \\
\text { vehicle }\end{array}$ & $\begin{array}{c}\text { Distance gap } \\
\text { (meter) }\end{array}$ \\
\hline 1 & 2 & young & female & 5.05 & car & 11.20 \\
\hline 2 & 1 & young & male & 2.79 & motorcycle & 4.40 \\
\hline 3 & 1 & young & male & 6.54 & motorcycle & 15.41 \\
\hline 4 & 2 & young & male & 3.77 & motorcycle & 9.10 \\
\hline 5 & 1 & young & female & 3.2 & motorcycle & 8.60 \\
\hline$\ldots$ & $\ldots$ & $\ldots$ & $\ldots$ & $\ldots$ & $\ldots$ & $\ldots$ \\
\hline 72 & 2 & old & female & 4.31 & motorcycle & 10.15 \\
\hline 73 & 1 & old & female & 4.09 & motorcycle & 9.64 \\
\hline 74 & 2 & old & male & 3.89 & motorcycle & 9.16 \\
\hline 75 & 3 & old & female & 3.33 & motorcycle & 7.85 \\
\hline 76 & 1 & old & female & 5.23 & motorcycle & 12.32 \\
\hline 77 & 1 & young & male & 2.8 & motorcycle & 6.60 \\
\hline
\end{tabular}


The selected intersection is an intersection where there is a continuous pedestrian crossing. The main variable discussed in this study is the gap between pedestrians with vehicles on the traffic flow in units of time. Other data variables observed were the number of pedestrians who crossed at one time, age categories (young and/or elderly), gender (male and/ or female), and the types of vehicle which the gap with the crossing pedestrians is measured to. Table 1 shows the details of observation data.

Four different methods are used in performing data processing. The methods have been used in previous research on critical gaps. The gap as a time that marks the beginning and end of every gap in the major currents is defined by Tian in [4]. In every crossing event, gap measurements begin when one or more pedestrians cross.

\subsection{Raff's method}

The calculation procedure is to find the probability value of each interval gap that exists, then poured into the form of graphs. The purpose of the probability here is the magnitude of the possibility of crossing at a time when the flow of traffic provides a certain gap value. In this study, the gap interval is set 0.5 seconds from 0 to 10 seconds for the time gap and 1.25 meters from 0 to 25 meters for the distance gap.

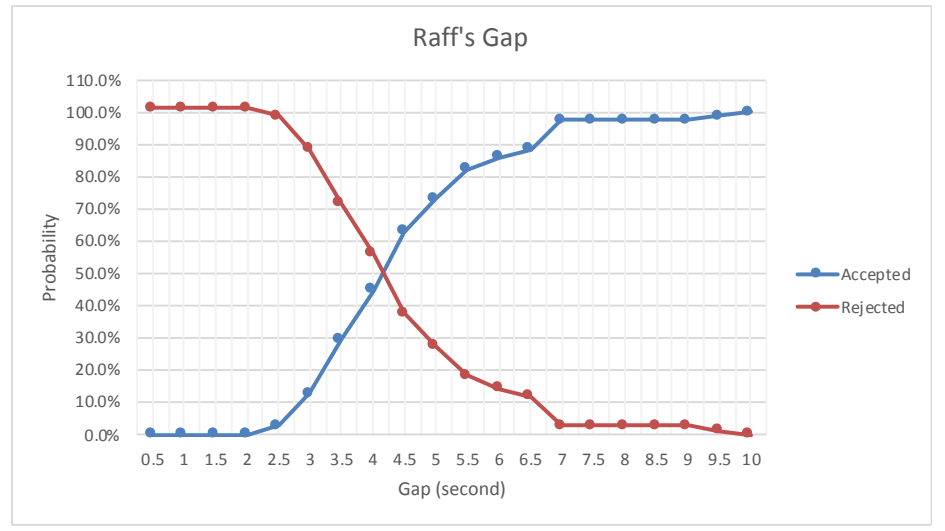

Fig. 1. Raff's graph.

In the graph above (Fig. 1) there are two lines, where the blue curve represents the acceptable gap probability, and the red curve represents the gap probability being rejected. While the yellow line indicates, the point of intersection between the gap probability curve is accepted with the gap probability curve rejected, whose position lies between the gap value of 4 and 4.5 seconds. The critical gap value can be seen from this point of intersection, where the gap probability is accepted, and the gap probability is rejected the same value. So the critical gap value for Raff method is 4.125 seconds.

\subsection{Harder's method}

Harder uses only one curve. This curve represents the accumulative number of crossings that can be done at each gap value interval. The author returns using a 0.5 -second gap range ranging from 0 to 10 seconds. The curve can be seen from Fig. 2 .

In this graph, the horizontal axis represents a large gap with an interval of 0.5 seconds, and the vertical axis represents the cumulative number of crossings for each gap quantity. The critical gap obtained from the Harder method is to draw a straight line at the 
accumulative crossing value of 50. Thus the critical gap obtained from this calculation is 4.6 seconds.

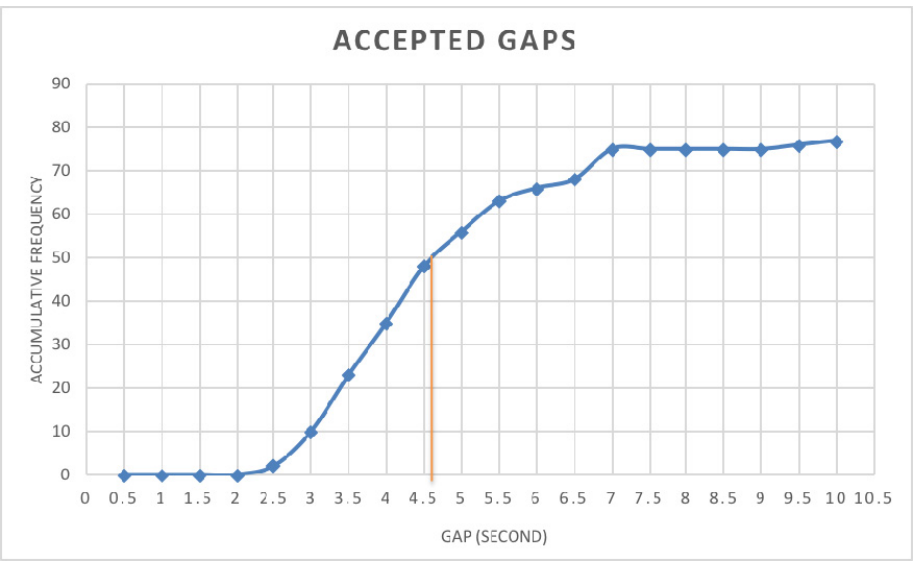

Fig. 2. Harder's graph.

\subsection{Wu's Method}

The theory underlying this method is the probability equilibrium between the rejected gap and the accepted gap. The main advantage of this method is that it can produce an accurate value of the critical gap without the need to use complex calculations like the Maximum Likelihood method released by Troutbeck in 1992 [9]. The equilibrium is generated macroscopically from the rejected cumulative gap distribution and the accepted gap. This method directly produces an empirical distribution of the critical gap (Table 2).

Table 2. Wu's calculation method.

\begin{tabular}{|c|c|c|c|c|c|c|c|c|c|c|}
\hline Gap t & $\mathbf{a ~ o r} \mathbf{r}$ & $\mathbf{n r}$ & $\mathbf{n a}$ & $\mathbf{F r}$ & $\mathbf{F a}$ & $\mathbf{F t c}$ & $\mathbf{p t c}$ & $\mathbf{t}_{\mathbf{d j}}$ & & $\mathbf{p t c} * \mathbf{t}$ \\
\hline 2.11 & $\mathrm{R}$ & 1 & 0 & 0.026 & 0 & 0 & 0 & 1.055 & & 0 \\
\hline 2.3 & $\mathrm{R}$ & 2 & 0 & 0.053 & 0 & 0 & 0 & 2.205 & & 0 \\
\hline 2.55 & $\mathrm{R}$ & 3 & 0 & 0.079 & 0 & 0 & 0 & 2.425 & & 0 \\
\hline$\ldots$ & $\ldots$ & $\ldots$ & $\ldots$ & $\ldots$ & $\ldots$ & $\ldots$ & $\ldots$ & $\ldots$ & $\ldots$ & $\ldots$ \\
\hline 6.89 & $\mathrm{~A}$ & 38 & 37 & 1 & 0.949 & 1 & 0 & 6.87 & & 0 \\
\hline 9.17 & $\mathrm{~A}$ & 38 & 38 & 1 & 0.974 & 1 & 0 & 8.03 & & 0 \\
\hline 9.53 & $\mathrm{a}$ & 38 & 39 & 1 & 1 & 1 & 0 & 9.35 & & 0 \\
\hline
\end{tabular}

The critical gap value is the result of the accumulation of the multiplication between the average gap value class (tdj) and the critical gap estimation frequency (ptc). The critical gap obtained from the calculation by $\mathrm{Wu}$ method is 4.101 seconds. Fa, Fr, and Ftc are probability distribution functions of acceptable gaps, rejected gaps, and critical gaps (Fig. $3)$. 


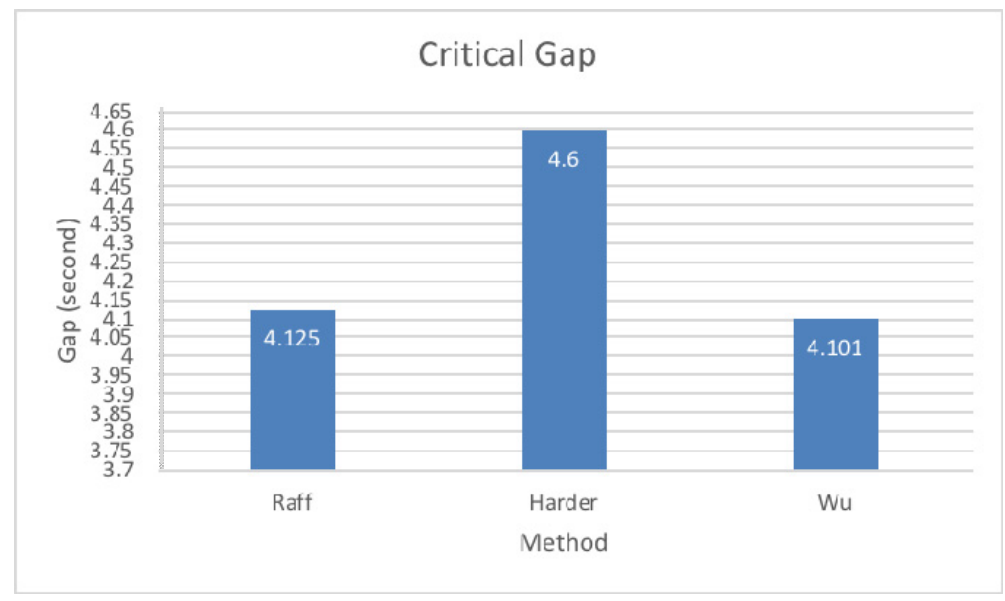

Fig. 3. Critical gaps.

Table 3. Methods comparison.

\begin{tabular}{|c|c|c|c|c|}
\hline Method & $\begin{array}{c}\text { Critical gap } \\
\text { (second) }\end{array}$ & Advantages & Limitation & $\begin{array}{c}\text { Additional } \\
\text { information }\end{array}$ \\
\hline Raff & 4.125 & $\begin{array}{c}\text { simple calculation } \\
\text { procedure, gap value } \\
\text { satisfactory } \\
\text { (accurate) }\end{array}$ & $\begin{array}{c}\text { data bias if pedestrians are } \\
\text { too cautious, depending on } \\
\text { the volume of traffic }\end{array}$ & $\begin{array}{c}\text { there are some } \\
\text { pedestrians who are } \\
\text { too cautious, several } \\
\text { times the volume of } \\
\text { traffic saturated }\end{array}$ \\
\hline Harder & 4.6 & $\begin{array}{c}\text { Simple calculation } \\
\text { procedure }\end{array}$ & $\begin{array}{c}\text { depending on the amount } \\
\text { of data, the over-estimated } \\
\text { gap value }\end{array}$ & $\begin{array}{c}\text { gap value is too high, } \\
\text { sample data is not } \\
\text { enough much }\end{array}$ \\
\hline $\mathrm{Wu}$ & 4.101 & $\begin{array}{c}\text { able to handle } \\
\text { inconsistent } \\
\text { pedestrians, } \\
\text { consistent and } \\
\text { accurate results }\end{array}$ & $\begin{array}{c}\text { gap value which should be } \\
\text { smaller than the value of } \\
\text { largest rejected gap }\end{array}$ & $\begin{array}{c}\text { need the least accepted } \\
\text { the data in this study }\end{array}$ \\
\hline
\end{tabular}

In another experiment done by Mohan et al. in India, the critical gap from Raff method is $3.10 \mathrm{~s}$, from Harder method is $3.65 \mathrm{~s}$, and from $\mathrm{Wu}$ method is $3.06 \mathrm{~s}$ [6]. The similarity between these two experiments is where Harder method results in an over-estimated critical gap. While Raff and Wu's method gave accurate and consistent results [6], Wu's method has advantages that can answer the weakness of the Raff's method, which can deal with pedestrians who are not consistent in doing crossings (Table 3). According to Mithun [6], this method provides consistent and accurate results following conditions in the field. The limitation on this method is to require the least accepted gap value that should be smaller than the largest rejected gap. These limits can be met by the data in this research, so the results obtained from the data calculated using the $\mathrm{Wu}$ method can be said to be valid and most accurate or following the actual conditions in the field. Thus the critical gap value of the data processing in this study is 4.101 seconds.

The variable of the crossers has a significance value of $0.574(>0.05)$ which means no significant effect on the gap value. Age category variable has significant value of 0.00 $(<0.05)$ which means a significant effect on the big gap. The gender variable has a sig 
value. 0.755 where this number is greater than the requirement of a variable significantly influence. Variable type of vehicle has significant value. Amounted to 0.833 which means the type of vehicle has no significant effect on the big gap.

The old categorized pedestrians are old-fashioned and slow-moving people. Pedestrians who fall into the young category have faster walking and response skills so they can accept smaller gaps. Judging from the difference between the two, it can be concluded that the age category variable significantly influences the gap.

\section{Conclusions}

Several methods can be used to estimate the magnitude of critical gaps in cross-walk cases each having characteristics, strengths, weaknesses, and limits. The author considers and analyzes the characteristics and outcomes of each method that the author uses. The method that best suits the actual conditions in the field is the Wu method with a critical gap of 4.101 seconds. Several variables influence the value of gap that is the number of crossers, age category, gender, and vehicle type. The variables that significantly influence the gap value are age categories.

This research is supported by research funds made available through the Research Fund of PITTA (Publikasi Internasional untuk Tugas Akhir Mahasiswa UI) of Universitas Indonesia, 2018, contract number: 2475/UN2.R3.1/HKP.05.00/2018.

\section{References}

1. World Health Organization. Pedestrian safety: a road safety manual for decisionmakers and practitioners (World Health Organization, 2013)

2. P. Dani. Kota tak ramah pejalan kaki itu bernama Jakarta. Kompas.com. Available at: https://properti.kompas.com/read/2017/08/21/174736021/kota-tak-ramah-pejalan-kakiitu-bernama-jakarta- (2017)

3. H.R. Agah. Konferensi Tahunan Teknik Jalan ke-4 (1990)

4. A. Kusuma, H.N. Koutsopoulos, Proc. Social and Behavioural Sci. 16 (2011)

5. H. Raff, A volume warrant for urban stop signs. (Eno Foundation for Higway Traffic Control, Saugatuck, 1950)

6. M. Mohan, S. Chandra, European Transport 61, 61 (2016)

7. M. Hemavathy, S. Kalaanidhi, K. Gunaseran, M. Advani, S. Velmurugan, Indian J. of Transport Man. 39, 4 (2015)

8. H. J. Amin, A.K. Maurya, Int. Transport Planning Soc. 9, 3 (2015)

9. N. Wu, TRB 2012 Annual Meeting (2012) 